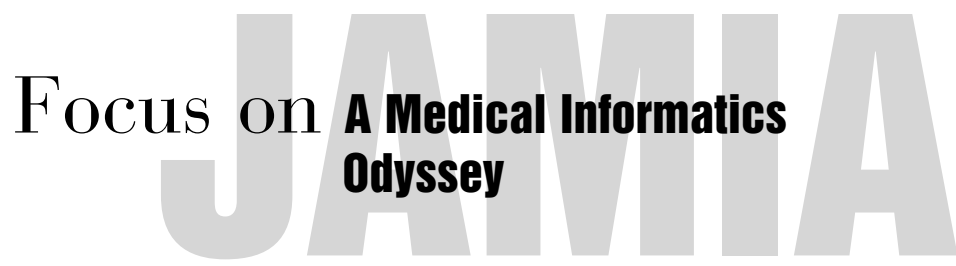

Introductory Comment

\section{Focus on a Medical Informatics Odyssey}

Since its inception at a time when medical informatics was a new field, the Symposium on Computer Applications in Medical Care (now known as the AMIA Symposium) has provided an opportunity for attendees to hear about pioneering work. As part of the 25th Annual Symposium that was held in November 2001, plenary speakers looked at the past and envisioned the future from four perspectives on medical informatics:

- Clinical Practice-G. Octo Barnett, MD, Clement McDonald, MD, and Rita Zielstorff, RN, MS

- Education-Edward H. Shortliffe, MD, PhD, and Peter Szolovits, PhD

- Research-Patricia Flatley Brennan, RN, PhD, Russ Altman, MD, PhD, and Isaac $\mathrm{S}$. Kohane, $\mathrm{MD}, \mathrm{PhD}$

- The Symposium-Donald A. B. Lindberg, MD, and Betsy L. Humphreys, MLS

The speakers were asked to prepare papers based on their presentations. The paper by Donald Lindberg and Betsy Humphreys appears here; additional papers will appear in subsequent issues of JAMIA. Video recordings of the actual presentations and other historical materials will be available on the AMIA Web site in a special history section. A grant from the National Library of Medicine supported the video recordings and collection of other materials suitable for learning about medical informatics history.

I encourage you to incorporate the JAMIA papers and the Web site not only into your own learning activities but also into curricula. We must take the lessons from the past into the future of medical informatics in order to contribute relevant solutions in our rapidly changing world. - SuZANNE BAKKEN, RN, DNSC, Chair, Scientific Program Committee, 2001 AMIA Symposium 